\title{
Prospective, randomized study of one, two, or three trabecular bypass stents in open- angle glaucoma subjects on topical hypotensive medication
}

\author{
This article was published in the following Dove Press journal: \\ Clinical Ophthalmology \\ II December 2015 \\ Number of times this article has been viewed
}

\section{Jay Katz' \\ Carl Erb² \\ Amadeu Carceller \\ Guillamet ${ }^{3}$ \\ Antonio $\mathrm{M} \mathrm{Fea}^{4}$ \\ Lilit Voskanyan ${ }^{5}$ \\ Jeffrey M Wells ${ }^{6}$ \\ Jane Ellen Giamporcaro ${ }^{6}$ \\ 'Wills Eye Hospital, Jefferson Medical College, Philadelphia, PA, USA; ${ }^{2}$ Eye Clinic Wittenbergplatz, Berlin, Germany; ${ }^{3}$ Department of Ophthalmology, Hospital d'Hebron, Barcelona, Spain; ${ }^{4}$ University Eye Clinic of the University of Turin, Turin, Italy; ${ }^{5} \mathrm{SV}$ Malayan Opthalmology Centre, Yerevan, Armenia; ${ }^{6}$ Glaukos Corporation, Laguna Hills, CA, USA}

Correspondence: L Jay Katz

Wills Eye Hospital, Suite II I0, I I th

floor, 840 Walnut Street, Philadelphia,

PA 19107, USA

Tel + I 2159283197

Email ljaykatz@gmail.com
Purpose: To assess the safety and efficacy of one, two, or three trabecular microbypass stents in eyes with primary open-angle glaucoma $(\mathrm{OAG})$ not controlled on ocular hypotensive medication. A total of 119 subjects were followed for 18 months postoperatively.

Materials and methods: Subjects with medicated intraocular pressure (IOP) $18-30 \mathrm{mmHg}$ and postmedication-washout baseline IOP $22-38 \mathrm{mmHg}$ were randomized to implantation of one, two, or three stents. Ocular hypotensive medication was to be used if postoperative IOP exceeded $18 \mathrm{mmHg}$.

Results: A total of 38 subjects were implanted with one stent, 41 subjects with two stents, and 40 subjects with three stents. Both month 12 IOP reduction $\geq 20 \%$ without ocular hypotensive medication vs baseline unmedicated IOP and month 12 unmedicated IOP $\leq 18 \mathrm{mmHg}$ were achieved by $89.2 \%, 90.2 \%$, and $92.1 \%$ of one-, two-, and three-stent eyes, respectively. Furthermore, $64.9 \%, 85.4 \%$, and $92.1 \%$ of the three respective groups achieved unmedicated IOP $\leq 15 \mathrm{mmHg}$. Over the 18-month follow-up period, medication was required in seven one-stent subjects, four two-stent subjects, and three three-stent subjects. At 18 months, mean unmedicated IOP was $15.9 \pm 0.9 \mathrm{mmHg}$ in one-stent subjects, $14.1 \pm 1.0 \mathrm{mmHg}$ in two-stent subjects, and $12.2 \pm 1.1 \mathrm{mmHg}$ in three-stent subjects. Month 18 IOP reduction was significantly greater $(P<0.001)$ with implantation of each additional stent, with mean differences in reduction of $1.84 \mathrm{mmHg}$ (95\% confidence interval 0.96-2.73) for three-stent vs two-stent groups and $1.73 \mathrm{mmHg}(95 \%$ confidence interval 0.83-2.64) for two-stent vs one-stent groups. Adverse events through 18 months were limited to cataract progression with best-corrected visual acuity loss and subsequent cataract surgery.

Conclusion: In this series, implantation of each additional stent resulted in significantly greater IOP reduction with reduced medication use. Titratability of stents as a sole procedure was shown to be effective and safe, with sustained effect through 18 months postoperatively in OAG not controlled with medication.

Keywords: iStent, MIGS, OAG, intraocular pressure, IOP reduction, multiple stents

\section{Introduction}

Glaucoma, a degenerative progressive disease causing optic nerve damage to approximately 60 million people worldwide, causes bilateral blindness in approximately 8.4 million. ${ }^{1}$ For many years preceding recent developments with microinvasive glaucoma surgery (MIGS), the standard surgical modality has been trabeculectomy, along with the various postoperative sequelae of hypotony, progression of cataract, and bleb and choroidal complications, with concomitant visual loss. ${ }^{2}$ The development of ab 
interno trabecular microbypass stents for use during MIGS has allowed patients with open-angle glaucoma (OAG) to experience significant reduction in both intraocular pressure (IOP) and medication usage, with lower risks and complications than with traditional incisional glaucoma surgery. ${ }^{3-7}$ While initial work has shown the benefits of MIGS implantation of one or multiple stents in conjunction with cataract surgery over the past 8 years, four recent prospective studies have focused on implantation of two trabecular microbypass stents as a stand-alone procedure - ie, in the absence of cataract surgery - with either presumptive administration of postoperative ocular hypotensive medication or with no postoperative medication. ${ }^{8-11}$ These two-stent sole-procedure studies have shown significant reductions in both IOP and medication use through 12 months.

The goal of the current study was to compare the effect of one, two, and three stents as a sole procedure on IOP and medication in subjects with OAG not controlled on two topical ocular hypotensive medications preoperatively. This report summarizes efficacy and safety data through 18 months postoperatively.

\section{Materials and methods Study design}

The study design was a prospective, randomized, controlled trial of one, two, or three trabecular microbypass stents (iStent $^{\circledR}$ Trabecular Micro-Bypass; Glaukos Corporation, Laguna Hills, CA, USA) in 120 eyes of 120 subjects enrolled at one clinical facility in Yerevan, Armenia. Ethical approval was obtained from the Armenian Ministry of Health. Study subjects signed an informed consent, and subject datacollection methods were followed in accordance with the Declaration of Helsinki, revised in 2008. The clinical trial registration number is NCT01517477 (ClinicalTrials.gov).

Subjects were required to have OAG (pigmentary and pseudoexfoliative were allowed) not controlled on two preoperative medications, with preoperative medicated IOP $\geq 18 \mathrm{mmHg}$ and $\leq 30 \mathrm{mmHg}$. The stage of glaucomatous optic neuropathy was to be mild to moderate, based on the structural and functional characteristics. The criteria used to diagnose glaucoma included the structural and functional deficits corresponding to typical glaucomatous abnormalities, and elevated IOP (between $18 \mathrm{mmHg}$ and $30 \mathrm{mmHg}$ while on medication and $>22 \mathrm{mmHg}$ without medication). Additional inclusion criteria were cup: $\operatorname{disk}(C: D)$ ratio $\leq 0.9$, normal angle anatomy, absence of peripheral anterior synechia, rubeosis, or other angle abnormalities that could impair proper stent placement, and a willingness to attend scheduled follow-up examinations for 5 years postoperatively. Exclusion criteria included pseudophakia with anterior-chamber intraocular lens, prior stent implantation in study eye, traumatic, uveitic, neovascular, or angle-closure glaucoma, glaucoma associated with vascular disorders, functionally significant visual field loss, prior incisional glaucoma surgery, prior selective laser trabeculoplasty within 90 days of screening, prior argon laser trabeculoplasty, iridectomy, or laser iridotomy, visual field status at risk by washout period, unmedicated IOP expected to be $>38 \mathrm{mmHg}$ after washout period, active corneal inflammation or edema, clinically significant corneal dystrophy, corneal surgery of any type, corneal opacities, congenital or traumatic cataract, retinal or optic nerve disorders, elevated episcleral venous pressure, clinically significant sequelae from trauma, chronic ocular inflammatory disease, best-corrected visual acuity (BCVA) worse than 20/200, fellow eye in the trial, and pregnant or nursing women.

Subjects from the clinic population who met the screening criteria were instructed to undergo a 4-week washout for prostaglandin analogs, $\beta$-blockers, and combination medications, a 2 -week washout for $\alpha$-adrenergic agonists, and a 5 -day washout for carbonic anhydrase inhibitors. Subsequent to the medication-washout period, IOP was measured again at the baseline examination. At this second preoperative examination following medication washout, IOP was required to be $\geq 22 \mathrm{mmHg}$ and $\leq 38 \mathrm{mmHg}$.

Subjects were to be randomized in a $1: 1: 1$ : ratio (40 subjects per group) to either the one-stent, two-stent, or threestent group. Randomization treatment assignments were generated using a pseudorandom number generator. Surgeries were performed by one staff surgeon (LV) and five visiting surgeons (JML, CE, ACG, AMF, and LJK) at the clinical facility in Armenia. The evaluation schedule was postoperative days 1 and 7 and months 1, 3, 6, 12, 18, 24, 30, 36, 42, 48, 54 , and 60. Postoperative ocular hypotensive medication was to be administered for elevated IOP (eg, IOP $>18 \mathrm{mmHg}$ ). Subjects on postoperative medication were required to undergo annual postoperative medication-washout periods at months $12,24,48$, and 60 , then return 1 month later for clinical evaluation and reinstitution of medication if needed. Postoperative examinations were conducted by the staff surgeon and investigational site staff.

\section{Stent and surgical technique}

The iStent is made of titanium, is heparin-coated, and is approximately $1.0 \mathrm{~mm}$ in length and $0.33 \mathrm{~mm}$ in height, with a snorkel bore diameter of $120 \mu \mathrm{m}$ (Figure 1). The 


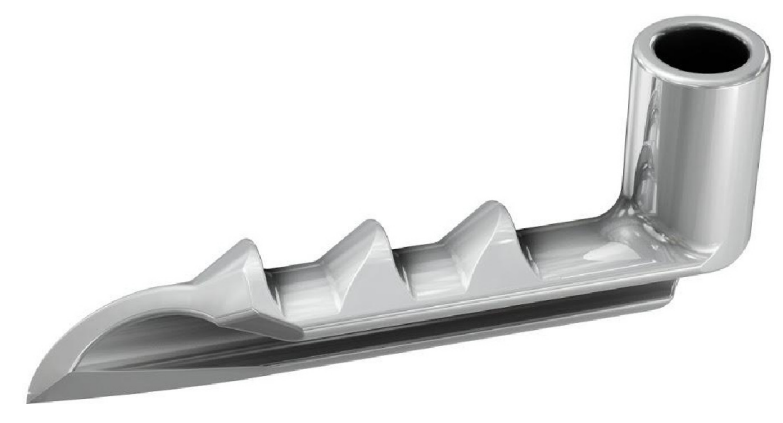

Figure I The iStent.

iStent comes preloaded in a customized single-use stainless steel inserter used to guide and release the stent directly into Schlemm's canal. The inserter features a release button activated by the surgeon to release the stent from the inserter.

Prior work by Samuelson et al has described the implantation technique. ${ }^{6}$ Eyes were anesthetized using topical anesthesia. The surgeon advanced the inserter through a $1.0 \mathrm{~mm}$ temporal clear corneal incision into the anterior chamber to approximately the pupillary margin. Under gonioprism visualization, the stent was gently guided through the trabecular meshwork and into Schlemm's canal at the nasal position. Implantation of subsequent stents (for the two-stent and three-stent surgeries) was similar to this method, with subsequent stent placement 1-2 clock hours away from the previous stent. At the end of each surgical procedure, subjects were administered topical antibiotic medication (moxifloxacin) and corticosteroid medication (dexamethasone $0.1 \%$ ). Subjects were prescribed the postoperative antibiotic medication for 1 week and corticosteroid medication for 4 weeks, tapered from four times per day to once a day over the 4-week period.

\section{Efficacy end points, safety, and data analyses}

The primary efficacy end point of the study was month 12 IOP reduction from baseline unmedicated IOP of $\geq 20 \%$, without use of topical ocular medications at 12 months and without secondary glaucoma surgical procedures by the 12-month visit. The secondary efficacy end point was month 12 IOP $\leq 18 \mathrm{mmHg}$ IOP, without use of topical ocular medications at 12 months and without secondary glaucoma surgical procedures by the 12 -month visit. Additional efficacy measures included proportional analyses of month $12 \mathrm{IOP} \leq 15 \mathrm{mmHg}$, without use of topical ocular medications at 12 months and without secondary glaucoma surgical procedures by the 12-month visit, mean IOP and medication usage through 18 months postoperatively, and month 18 unmedicated mean
IOP and change in IOP from preoperative values. Safety analyses included assessment of BCVA, visual field via perimetry, slit-lamp evaluation, $\mathrm{C}: \mathrm{D}$ ratio estimation, corneal thickness via pachymetry, complications, and ocular adverse events in all 119 eyes through 18 months postoperatively.

The intent-to-treat (ITT) population included all qualified, randomized subjects who underwent stent-implantation surgery. Demographic and preoperative characteristics and safety analyses were summarized for the ITT population. The modified ITT population included the subset of subjects who did not undergo cataract surgery prior to month 12 . Proportional analyses of IOP reduction $\geq 20 \%$, IOP $\leq 18 \mathrm{mmHg}$, and IOP $\leq 15 \mathrm{mmHg}$ were performed on the modified ITT population. For these analyses, exact $95 \%$ confidence intervals (CIs) based on a binomial distribution were calculated for responder rates. Analyses of mean IOP at each postoperative exam were conducted on the number of available eyes at each exam that had not undergone secondary surgical interventions that might confound results. For these and other continuous variables, mean and standard deviation were provided. Tukey's pairwise multiple-comparison test was performed to assess IOP reduction at month 18 between each of the two-stent and three-stent groups. For categorical outcomes, counts and percentages were calculated. All statistical tests were performed using PC-SAS ${ }^{\circledR}$ software version 9.3 (SAS Institute Inc., Cary, NC, USA).

\section{Results}

\section{Subject disposition and demographics}

A total of 251 subjects were screened for the study, and 152 proceeded to medication washout and the baseline exam. Of the 152 subjects, 33 did not pass the baseline exam (IOP not in range after medication washout, or not did not complete medication washout). The remaining qualified subjects were randomized to implantation of one stent $(\mathrm{n}=38)$, two stents $(n=41)$, or three stents $(n=40)$. These subjects comprised the ITT population. Complete records through 18 months postoperatively are available for all 119 subjects.

All subjects were Caucasian. In the one-stent group, the mean ( \pm standard deviation) age of the 27 men and eleven women was $68.1 \pm 9.1$ years, and most eyes $(n=23)$ were right eyes (Table 1). All eyes had a diagnosis of primary OAG. One eye in the one-stent group was pseudophakic, and the remaining eyes were phakic. The mean visual field (mean deviation) was $-4.72 \pm 4.42 \mathrm{~dB}$, the mean C:D ratio was $0.68 \pm 0.11$, and the mean corneal thickness was $528.4 \pm 34.3 \mu \mathrm{m}$. As per the inclusion criterion to qualify for the study, subjects were on two preoperative medications. Prior to the screening exam, 
Table I Demographics and preoperative characteristics: ITT population

\begin{tabular}{|c|c|c|c|}
\hline & One-stent group $(n=38)$ & Two-stent group $(n=4 I)$ & Three-stent group $(n=40)$ \\
\hline Age (years), mean $\pm S D$; range & $68.1 \pm 9.1 ; 49-83$ & $67.8 \pm 9.3 ; 51-83$ & $60.9 \pm 8.1 ; 49-85$ \\
\hline Sex, male/female & $27 / 11$ & $19 / 22$ & $19 / 20$ \\
\hline Race, white/other & $38 / 0$ & $4 I / 0$ & $39 / 0$ \\
\hline Eye, OD/OS & $23 / 15$ & $21 / 20$ & $17 / 23$ \\
\hline Glaucoma diagnosis, POAG/PEX & $38 / 0$ & $40 / 1$ & $39 / 0$ \\
\hline Lens status, phakic/pseudophakic & $37 / 1$ & $4 I / 0$ & $38 / 1$ \\
\hline Visual field, $M D(d B)$, mean $\pm S D$ & $-4.72 \pm 4.42$ & $-5.20 \pm 5.65$ & $-4.8 I \pm 4.22$ \\
\hline$C: D$ ratio, mean $\pm S D$ & $0.68 \pm 0.11$ & $0.7 I \pm 0.14$ & $0.70 \pm 0.12$ \\
\hline Pachymetry $(\mu \mathrm{m})$, mean $\pm S D$ & $528.4 \pm 34.3$ & $54 I . I \pm 38.3$ & $523.3 \pm 37.0$ \\
\hline Number of medications at screening,' mean \pm SD & $1.7 \mathrm{I} \pm 0.6 \mathrm{I}$ & $1.76 \pm 0.54$ & $1.51 \pm 0.69$ \\
\hline Preoperative medicated IOP $(\mathrm{mmHg})$, mean \pm SD & $19.8 \pm 1.3$ & $20.1 \pm 1.6$ & $20.4 \pm 1.8$ \\
\hline Postwashout IOP $(\mathrm{mmHg})$, mean \pm SD & $25.0 \pm I . I$ & $25.0 \pm 1.7$ & $25.1 \pm 1.9$ \\
\hline BCVA (logMAR), mean $\pm S D$ & $0.28 \pm 0.34$ & $0.39 \pm 0.40$ & $0.24 \pm 0.35$ \\
\hline
\end{tabular}

Notes: 'All subjects qualified for the study based on the use of two medications. Some subjects stopped medication use prior to the screening visit. The mean (SD) values for number of medications at screening reflect the medications subjects were taking at the time of the screening exam.

Abbreviations: ITT, intent-to-treat; SD, standard deviation; OD, oculus dexter (right eye); OS, oculus sinister (left eye); POAG, primary open-angle glaucoma; PEX, pseudoexfoliative glaucoma; MD, mean deviation; C:D, cup:disk; IOP, intraocular pressure; BCVA, best-corrected visual acuity; MAR, minimum angle of resolution.

a subset of subjects had discontinued medication use. At the time of the screening exam, the mean number of medications was $1.71 \pm 0.61$. The average medicated IOP at this exam was $19.8 \pm 1.3 \mathrm{mmHg}$, and mean baseline IOP after medication washout was $25.0 \pm 1.1 \mathrm{mmHg}$. Mean preoperative BCVA (logarithm of minimum angle of resolution) was $0.28 \pm 0.34$. Demographic and preoperative characteristics for the twostent and three-stent groups were similar to those for the one-stent group (Table 1).

\section{Intraocular pressure and medication use}

Both the primary and secondary efficacy end points were achieved by $89.2 \%$ of one-stent, $90.2 \%$ of two-stent, and $92.1 \%$ of three-stent subjects (Table 2 and Figure 2). Month 12 IOP $\leq 15 \mathrm{mmHg}$ without medication was achieved by $64.9 \%(n=24,95 \%$ CI $47.5 \%-79.8 \%)$ of one-stent subjects, $85.4 \%$ ( $n=35,95 \%$ CI 70.8\%-94.4\%) of two-stent subjects, and $92.1 \%(n=35,95 \%$ CI $78.6 \%-98.3 \%)$ of three-stent subjects. Seven subjects in the one-stent group, four subjects in the two-stent group, and three subjects in the three-stent group required postoperative medication due to elevated
IOP at visits ranging from month 1 to month 18 (Table 3). Thirteen of the 14 subjects were prescribed one medication, and one subject in the two-stent group was prescribed two medications.

Mean IOP over time and proportion of eyes on medication over time are shown in Table 4. Following a 1-month medication washout at month 12 for those eyes on medication, mean unmedicated IOP at months $12-13$ was $14.9 \pm 1.9 \mathrm{mmHg}$, $13.6 \pm 2.1 \mathrm{mmHg}$, and $12.7 \pm 2.1 \mathrm{mmHg}$ in the three respective groups. IOP reduction was sustained in each of the groups throughout the 18-month postoperative period, with greater reduction in the multiple-stent groups vs the one-stent group. At 18 months, mean IOP was $15.6 \pm 1.5 \mathrm{mmHg}$ in the one-stent group, $13.8 \pm 1.3 \mathrm{mmHg}$ in the two-stent group, and $12.1 \pm 1.2 \mathrm{mmHg}$ in the three-stent group. For eyes on no medication at month 18 , IOP was $15.9 \pm 0.9 \mathrm{mmHg}$, $14.1 \pm 1.0 \mathrm{mmHg}$, and $12.2 \pm 1.1 \mathrm{mmHg}$ in the three respective groups, representing IOP decreases of $36.1 \%, 43.2 \%$, and $50.6 \%$ from baseline (Table 5). Each of the three pairwise comparisons of IOP reduction was significant $(P<0.001)$, with mean differences in reduction of $3.58 \mathrm{mmHg}(95 \%$

Table 2 Proportional analyses of month I2 IOP without medication: modified ITT population

\begin{tabular}{|c|c|c|c|}
\hline Month I2 IOP & $\begin{array}{l}\text { One-stent group }(n=37), n(\%) \\
(95 \% \mathrm{Cl})\end{array}$ & $\begin{array}{l}\text { Two-stent group }(n=4 I), n(\%) \\
(95 \% \mathrm{Cl})\end{array}$ & $\begin{array}{l}\text { Three-stent group }(n=38), n(\%) \\
(95 \% \mathrm{Cl})\end{array}$ \\
\hline IOP reduction $\geq 20 \%$ vs baseline IOP & $\begin{array}{l}33(89.2 \%) \\
(74.6 \%-97.0 \%)\end{array}$ & $\begin{array}{l}37(90.2 \%) \\
(76.9 \%-97.3 \%)\end{array}$ & $\begin{array}{l}35(92.1 \%) \\
(78.6 \%-98.3 \%)\end{array}$ \\
\hline $\mathrm{IOP} \leq 18 \mathrm{mmHg}$ & $\begin{array}{l}33(89.2 \%) \\
(74.6 \%-97.0 \%)\end{array}$ & $\begin{array}{l}37(90.2 \%) \\
(76.9 \%-97.3 \%)\end{array}$ & $\begin{array}{l}35(92.1 \%) \\
(78.6 \%-98.3 \%)\end{array}$ \\
\hline $\mathrm{IOP} \leq 15 \mathrm{mmHg}$ & $\begin{array}{l}24(64.9 \%) \\
(47.5 \%-79.8 \%)\end{array}$ & $\begin{array}{l}35(85.4 \%) \\
(70.8 \%-94.4 \%)\end{array}$ & $\begin{array}{l}35(92.1 \%) \\
(78.6 \%-98.3 \%)\end{array}$ \\
\hline
\end{tabular}

Abbreviations: IOP, intraocular pressure; ITT, intent-to-treat; $\mathrm{Cl}$, confidence interval. 


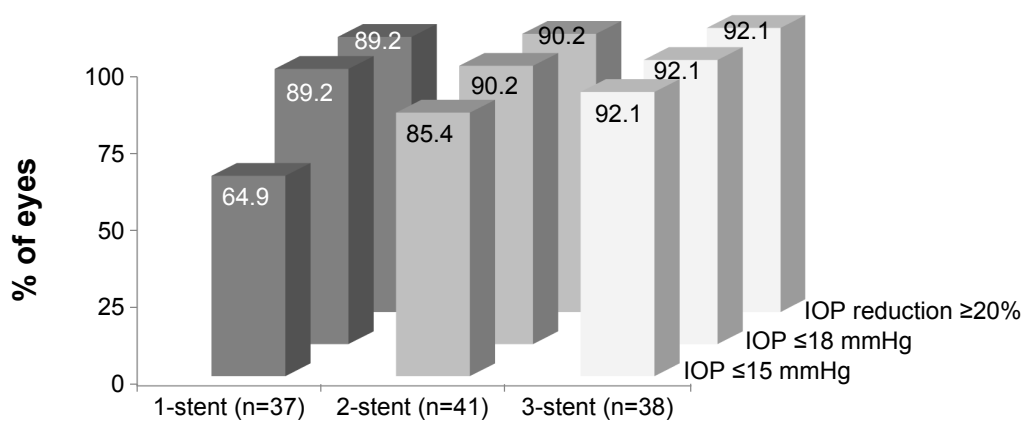

Figure 2 Proportional analyses of month I2 IOP without medication: modified ITT population.

Abbreviations: IOP, intraocular pressure; ITT, intent-to-treat.

CI 2.66-4.49) for the three-stent vs one-stent groups, $1.84 \mathrm{mmHg}(95 \% \mathrm{CI} 0.96-2.73)$ for the three-stent vs twostent groups, and $1.73 \mathrm{mmHg}(95 \% \mathrm{CI} 0.83-2.64)$ for the two-stent vs one-stent groups (Figure 3).

\section{Safety assessment}

No intraoperative ocular adverse events occurred, including possible intraoperative adverse events, such as hyphema, iris damage, or corneal injury, or failure to implant stents. By month 18, four eyes (two each in the one-stent and threestent groups) underwent cataract surgery due to progression of cataract. In general, BCVA, C:D ratio, and visual field values did not appear to be different at 2 years postoperatively vs preoperative levels. No other adverse events or secondary glaucoma surgeries were reported. At 18 months, $79 \%$

Table 3 Detail of subjects with postoperative medication added

\begin{tabular}{cll}
\hline $\begin{array}{l}\text { Subject } \\
\text { identification }\end{array}$ & $\begin{array}{l}\text { Postoperative exam } \\
\text { when medication' added }\end{array}$ & $\begin{array}{l}\text { IOP when } \\
\text { medication added }\end{array}$ \\
\hline $\begin{array}{l}\text { One-stent group } \\
8\end{array}$ & Month I & $21 \mathrm{mmHg}$ \\
63 & Month 3 & $19 \mathrm{mmHg}$ \\
80 & Month 3 & $19 \mathrm{mmHg}$ \\
5 & Month 6 & $19 \mathrm{mmHg}$ \\
10 & Month 18 & $17.7 \mathrm{mmHg}$ \\
51 & Month 18 & $18.3 \mathrm{mmHg}$ \\
101 & Month 18 & $18 \mathrm{mmHg}$ \\
Two-stent group & & \\
87 & Month 31 & $20 \mathrm{mmHg}$ \\
94 & Month 6 & $19 \mathrm{mmHg}$ \\
107 & Month 6 & $18.7 \mathrm{mmHg}$ \\
119 & Month 6 & $19 \mathrm{mmHg}$ \\
Three-stent group & & $18 \mathrm{mmHg}$ \\
92 & Month 3 & $19 \mathrm{mmHg}$ \\
71 & Month 6 & $18.3 \mathrm{mmHg}$ \\
74 & Month 6 & \\
\hline
\end{tabular}

Notes: 'Subject 87 was prescribed two medications at the end of the month 3 exam. All other subjects were prescribed one medication.

Abbreviation: IOP, intraocular pressure. of eyes in the one-stent group achieved BCVA of 20/40 or better vs $68 \%$ at the preoperative visit (Table 6). In each of the three groups, mean $\mathrm{C}: \mathrm{D}$ ratio values at month 18 were the same as preoperative values. The mean visual field (mean deviation) values at 18 months of $-4.9 \pm 4.71 \mathrm{~dB}$ (one stent), $-5.96 \pm 5.84 \mathrm{~dB}$ (two stents), and $-5.24 \pm 4.13 \mathrm{~dB}$ (three stents) were also generally similar to preoperative values.

\section{Discussion}

In the 15 years since trabecular bypass surgery was reported to be a viable method for aqueous outflow, laboratory and clinical research efforts have generated solid evidence to establish the safety and efficacy of MIGS with trabecular bypass stents up to 5 years postoperatively. ${ }^{3-15}$ Original clinical work consisted of stent implantation in conjunction with cataract surgery with either one or multiple stents, while more recent work has involved stent surgery as a sole procedure.

The basis for incremental efficacy with use of multiple stents has been established previously in laboratory work. ${ }^{13-15}$ Work by Hunter et al estimated reduction in IOP of $6 \mathrm{mmHg}$ and reduction in total outflow resistance of $30 \%$ with a single stent, whereas IOP and outflow resistance reduced $8.9 \mathrm{mmHg}$ and $44 \%$, respectively, with the use of two stents. ${ }^{15}$ Similarly, Bahler et al estimated decreases of IOP of $6.1 \mathrm{mmHg}$ with one iStent and $9.7 \mathrm{mmHg}$ with two stents. ${ }^{13}$ This current clinical study is consistent with the laboratory findings, in that a single stent lowered IOP by $36.1 \%$ and two stents afforded a $43.2 \%$ reduction. Furthermore, the use of three stents resulted in IOP reduction of $50.6 \%$. Therefore, the laboratory research is corroborated by this clinical report.

The findings with multiple-stent use in this current study are directionally consistent with earlier work by Belovay et al of two or three iStents during cataract surgery. They showed $70 \%$ of patients achieving an IOP of $\leq 15 \mathrm{mmHg}$ and $83 \%$ of subjects experiencing a reduction in hypotensive medication 
Table 4 Mean IOP $(\mathrm{mmHg})$ and proportion of eyes on medications: available eyes at each exam'

\begin{tabular}{|c|c|c|c|c|c|c|c|c|}
\hline & Screening & Baseline & Month I & Month 3 & Month 6 & Month 12 & Months I2-132 & Month 18 \\
\hline \multicolumn{9}{|l|}{ One-stent group } \\
\hline $\mathrm{n}$ & 38 & 38 & 38 & 38 & 38 & 37 & 37 & 36 \\
\hline Mean IOP (SD) & $19.8(1.3)$ & $25.0(I . I)$ & $12.2(3.1)$ & $12.8(2.3)$ & I3.I (I.7) & I4.4 (I.2) & $14.9(1.9)$ & $15.6(1.5)$ \\
\hline On medication, $\mathrm{n}(\%)$ & $38(100 \%)$ & $0(0 \%)$ & $0(0 \%)$ & I (2.6\%) & $3(7.9 \%)$ & $4(10.8 \%)$ & $0(0 \%)$ & $4(11.1 \%)$ \\
\hline \multicolumn{9}{|l|}{ Two-stent group } \\
\hline $\mathrm{n}$ & $4 I$ & $4 I$ & 41 & 41 & 41 & 41 & 41 & 41 \\
\hline Mean IOP (SD) & $20.1(1.6)$ & $25.0(1.7)$ & $12.5(2.7)$ & $13.0(2.1)$ & $13.5(2.3)$ & $12.8(1.4)$ & $13.6(2.1)$ & I3.8 (I.3) \\
\hline On medication, $\mathrm{n}(\%)$ & $4 \mathrm{I}(100 \%)$ & $0(0 \%)$ & $0(0 \%)$ & $0(0 \%)$ & I (2.4\%) & $4(9.8 \%)$ & $0(0 \%)$ & $4(9.8 \%)$ \\
\hline \multicolumn{9}{|l|}{ Three-stent group } \\
\hline $\mathrm{n}$ & 40 & 40 & 40 & 40 & 40 & 38 & 38 & 38 \\
\hline Mean IOP (SD) & $20.4(1.8)$ & $25.1(1.9)$ & $12.0(2.7)$ & $12.8(2.0)$ & $12.9(2.0)$ & $12.2(1.5)$ & $12.7(2.1)$ & I2.I (I.2) \\
\hline On medication, n (\%) & 40 (100\%) & $0(0 \%)$ & $0(0 \%)$ & $0(0 \%)$ & I (2.5\%) & $3(7.9 \%)$ & $0(0 \%)$ & $3(7.9 \%)$ \\
\hline
\end{tabular}

Notes: 'IOP and medication data at the start of the exam are reported. Data were included for subjects who had not undergone secondary surgical interventions that might confound results. ${ }^{2}$ Eleven eyes were washed out of medication at month 12 . Months $12-13$ IOP = month 12 IOP for I05 eyes on no medication, and month 13 IOP for eleven eyes washed out of medication at month 12 .

Abbreviations: IOP, intraocular pressure; SD, standard deviation.

use at 1 year postoperatively. ${ }^{3}$ In our study, more than $80 \%$ of subjects were able to eliminate medication use. Moreover, in comparison to Belovay et al's work and others that have shown the benefit of iStent implantation in conjunction with cataract surgery, our study evaluated the effects of stent implantation as a stand-alone procedure, thus allowing for evaluation of the effect of stent implantation on IOP reduction without the confounding effect of cataract surgery. Furthermore, while an earlier study by the MIGS study group of two stents plus one postoperative medication in patients with OAG not controlled on two preoperative medications showed month 12 IOP reduction $\geq 20 \%$ from baseline and month 12 IOP $\leq 18 \mathrm{mmHg}$ with decrease of one medication in all patients, ${ }^{8}$ our study design evaluated outcomes after stent surgery without the use of postoperative medication.

To our knowledge, this prospective, randomized study to assess comparatively one, two, and three stents as the sole therapy in OAG eyes is the first ophthalmic medical device study to randomize subjects to receive single vs multiple surgical devices. While over $80 \%$ of subjects attained both the primary end point of month 12 IOP reduction without medication of $\geq 20 \%$ from baseline unmedicated IOP and the secondary end point of month 12 IOP $\leq 18 \mathrm{mmHg}$ without medication, a greater percentage of multiple-stent subjects vs the single-stent group showed month $12 \mathrm{IOP} \leq 15 \mathrm{mmHg}$. Furthermore, with the use of each additional stent, mean IOP through 18 months was lower, and IOP reduction at month 18 was significantly greater. Therefore, these data validate the increased circumferential flow within Schlemm's canal via use of multiple stents vs one stent to achieve greater levels of IOP reduction.

Additional IOP reduction to levels lower than $15 \mathrm{mmHg}$ is desirable in certain cases where target pressures are required in an attempt to retard disease progression. The National Eye Institute-sponsored AGIS study confirmed the association between low IOP and reduced progression of glaucomatous damage in advanced OAG patients. ${ }^{16}$ Our study showed that two stents can provide IOP decrease to less than $15 \mathrm{mmHg}$ with minimal disruption to the ocular anatomy. For patients requiring even lower IOP, surgeons can enhance the two-stent therapy with either an additional medication or an additional stent.

The safety data were very favorable, with no patients experiencing complications or adverse events commonly associated with conventional glaucoma procedures, such as endophthalmitis, bleb formation, hypotony, and fibrosis. Overall, BCVA, visual field measures, and C:D ratio did not appear different from preoperative values. With only one stent contained in each inserter, implantation of

Table 5 Month 18 mean IOP and change in mean IOP vs screening and baseline exams: available eyes' ${ }^{\prime}$ without medication

\begin{tabular}{llll}
\hline Mean IOP and change in mean IOP at month I8 & One-stent group, $\mathbf{n}=\mathbf{3 2}$ & Two-stent group, $\mathbf{n}=\mathbf{3 7}$ & Three-stent group, $\mathbf{n}=\mathbf{3 5}$ \\
\hline Mean \pm SD IOP for eyes without medication $(\mathrm{mmHg})$ & $15.93 \pm 0.90$ & $14.07 \pm 1.00$ & $12.24 \pm 1.12$ \\
Change (\%) from screening medicated IOP $(\mathrm{mmHg})$ & $-3.94(-19.5)$ & $-5.99(-29.5)$ & $-8.19(-39.7)$ \\
Change (\%) from baseline unmedicated IOP $(\mathrm{mmHg})$ & $-9.04(-36.1)$ & $-10.77(-43.2)$ & $-12.61(-50.6)$ \\
\hline
\end{tabular}

Note: 'Data were included for subjects who had not undergone secondary surgical interventions that might confound results.

Abbreviations: IOP, intraocular pressure; SD, standard deviation. 


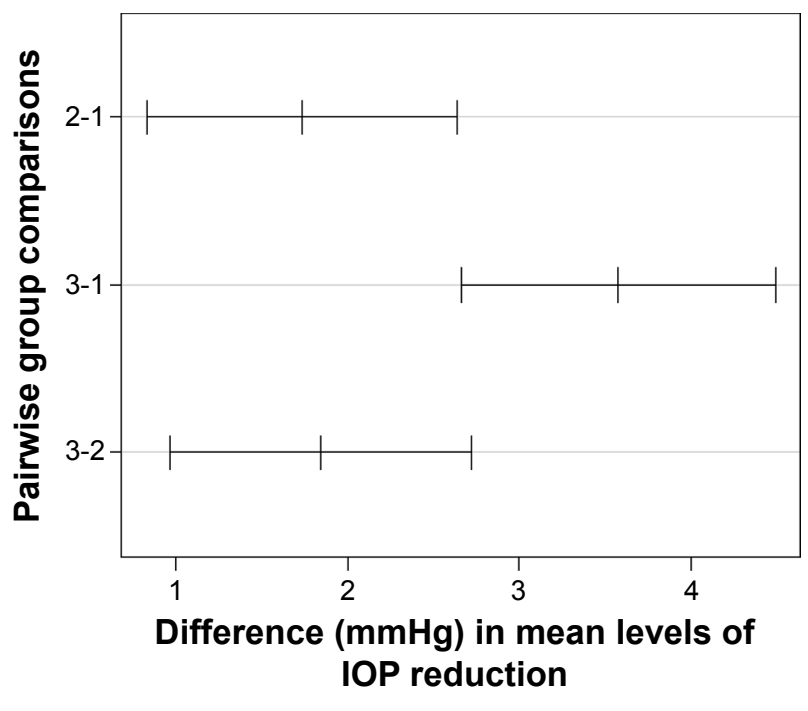

Figure 3 Pairwise group comparisons of month 18 unmedicated IOP reduction. Abbreviation: IOP, intraocular pressure.

multiple stents increased the number of insertion steps per eye. Despite the additional steps, safety data were similar across stent groups.

Limitations of this study include enrollment of a Caucasian population only, an open-label study design, a single-site study, and lack of masking to the study-treatment groups. The qualifying IOP at the baseline visit was not measured on multiple days, which may raise questions about regression to the mean. Furthermore, this study did not examine postural considerations of IOP measurements. It has been shown that IOP measurements are generally not affected in trabeculectomy-treated eyes, but that canaloplasty-treated eyes have higher IOP measured in a supine position than in a sitting position. ${ }^{17}$ Future studies may incorporate multiple centers with multiple measures of IOP, and could also examine the postural effect on IOP measurements. The cost of the implant was not factored into the study design, although this factor would be an important consideration in one's practice. Finally, this report summarizes data through 18 months. A future report from this study could encompass longer postoperative follow-up through 5 years postoperatively. Still, the IOP reduction reported initially after surgery was shown to be sustained over the postoperative follow-up period.

In conclusion, this ongoing, prospective, randomized study showed sustained efficacy through 18 months after single or multiple iStents as the sole therapy in patients with OAG, with equivalent overall safety. Two stents offered significantly greater IOP reduction vs a single-stent implantation that was sustained through the postoperative follow-up, and three stents offered greater reduction vs two stents, thus demonstrating stent implantation as a titratable therapy that can be tailored for patients to achieve even lower target pressures depending on severity and/or progression of OAG. In doing so, the study validates the future role and promise of multistent injectable therapy in a preloaded device, such as the next-generation trabecular microbypass stents. Future reports will continue to evaluate long-term advantages of single vs multiple trabecular microbypass stents as viable therapy for OAG.

\section{Acknowledgments}

Funding for this research was provided by the study sponsor, Glaukos Corporation, Laguna Hills, CA. The authors acknowledge Jeffrey M Liebmann, MD, who participated in the study as one of the visiting surgeons who performed surgery on study subjects. This paper was presented in part at the 2015 Annual Meeting of the American Glaucoma Society and the 2015 Annual Meeting of the American Society of Cataract and Refractive Surgeons, and accepted for presentation in part at the 2015 Annual Meeting of the European Society of Cataract and Refractive Surgeons.

Table 6 BCVA by visit: ITT population

\begin{tabular}{|c|c|c|c|c|c|c|}
\hline & Preoperative & Month I & Month 3 & Month 6 & Month I 2 & Month I8 \\
\hline \multicolumn{7}{|c|}{ One-stent group $(n=38)$} \\
\hline $20 / 40$ or better & $26(68 \%)$ & $28(74 \%)$ & $29(76 \%)$ & $28(74 \%)$ & $29(76 \%)$ & $30(79 \%)$ \\
\hline $20 / 100$ or better & $33(87 \%)$ & $33(87 \%)$ & $33(87 \%)$ & $33(87 \%)$ & $34(89 \%)$ & $34(89 \%)$ \\
\hline $20 / 200$ or better & $38(100 \%)$ & $38(100 \%)$ & $38(100 \%)$ & $38(100 \%)$ & $38(100 \%)$ & $38(100 \%)$ \\
\hline \multicolumn{7}{|c|}{ Two-stent group $(n=4 I)$} \\
\hline $20 / 40$ or better & $25(61 \%)$ & $27(66 \%)$ & $27(66 \%)$ & $27(66 \%)$ & $27(66 \%)$ & $27(66 \%)$ \\
\hline $20 / 100$ or better & $31(76 \%)$ & $33(80 \%)$ & $33(80 \%)$ & $33(80 \%)$ & $33(80 \%)$ & $33(80 \%)$ \\
\hline $20 / 200$ or better & $4 I(100 \%)$ & $4 I(100 \%)$ & $4 \mathrm{I}(100 \%)$ & 41 (100\%) & $41(100 \%)$ & $4 \mathrm{I}(100 \%)$ \\
\hline \multicolumn{7}{|c|}{ Three-stent group $(n=40)$} \\
\hline $20 / 40$ or better & $29(73 \%)$ & $31(78 \%)$ & $31(78 \%)$ & $31(78 \%)$ & $32(80 \%)$ & $32(80 \%)$ \\
\hline $20 / 100$ or better & 35 (88\%) & 35 (88\%) & $35(88 \%)$ & $35(88 \%)$ & 35 (88\%) & 35 (88\%) \\
\hline $20 / 200$ or better & $40(100 \%)$ & $40(100 \%)$ & 40 (100\%) & 40 (I00\%) & 40 (100\%) & $40(100 \%)$ \\
\hline
\end{tabular}

Abbreviations: BCVA, best-corrected visual acuity; ITT, intent-to-treat. 


\section{Disclosure}

LJK, CE, ACG, and AMF received nonfinancial support from Glaukos for their work as investigators in the study. LV received financial support from Glaukos for her work as an investigator in this study. LJK received financial support from Glaukos for his work as a medical monitor for this study. AMF and LJK have also received nonstudy financial support from Glaukos. JMW and JEG are employees of Glaukos. The authors report no other conflicts of interest in this work.

\section{References}

1. Quigley HA. Glaucoma. Lancet. 2011;377:1367-1377.

2. Rulli E, Biagioli E, Riva I, et al. Efficacy and safety of trabeculectomy vs nonpenetrating surgical procedures: a systematic review and meta-analysis. JAMA Ophthalmol. 2013;131:1573-1582.

3. Belovay GW, Naqi A, Chan BJ, Rateb M, Ahmed II. Using multiple trabecular micro-bypass stents in cataract patients to treat open-angle glaucoma. J Cataract Refract Surg. 2012;38:1911-1917.

4. Craven ER, Katz LJ, Wells JM, Giamporcaro JE. Cataract surgery with trabecular micro-bypass stent implantation in patients with mild-to-moderate open-angle glaucoma and cataract: two-year follow-up. J Cataract Refract Surg. 2012;38:1339-1345.

5. Fea AM. Phacoemulsification versus phacoemulsification with microbypass stent implantation in primary open-angle glaucoma. $J$ Cataract Refract Surg. 2010;36:407-412.

6. Samuelson TW, Katz LJ, Wells JM, Duh YJ, Giamporcaro JE. Randomized evaluation of the trabecular micro-bypass stent with phacoemulsification in patients with glaucoma and cataract. Ophthalmology. 2011;118:459-467.

7. Arriola-Villalobos P, Martínez-de-la-Casa JM, Díaz-Valle D, FernándezPérez C, García-Sánchez J, García-Feijoó J. Combined iStent trabecular micro-bypass stent implantation and phacoemulsification for coexistent open-angle glaucoma and cataract: a long-term study. Br J Ophthalmol. 2012;96:645-649.
8. Ahmed II, Katz LJ, Chang DF, et al. Prospective evaluation of microinvasive glaucoma surgery with trabecular microbypass stents and prostaglandin in open-angle glaucoma. J Cataract Refract Surg. 2014;40:1295-1300.

9. Voskanyan L, García-Feijoó J, Belda JI, Fea A, Jünemann A, Baudouin C. Prospective, unmasked evaluation of the iStent inject system for open-angle glaucoma: synergy trial. Adv Ther. 2014;31: 189-201.

10. Fea AM, Belda JI, Rekas M, et al. Prospective unmasked randomized evaluation of the iStent inject ${ }^{\mathbb{E}}$ versus two ocular hypotensive agents in patients with primary open-angle glaucoma. Clin Ophthalmol. 2014; 8:875-882.

11. Samuelson TW. Phakic or pseudophakic OAG subjects implanted with 2 trabecular bypass stents: 18-month findings. Poster presented at: ASCRS-ASOA Symposium and Congress; April 25-29, 2014; Boston, MA.

12. Spiegel D, Kobuch K. Trabecular meshwork bypass tube shunt: initial case series. Br J Ophthalmol. 2002;86:1228-1231.

13. Bahler C, Smedley G, Zhou J, Johnson D. Trabecular bypass stents decrease intraocular pressure in cultured human anterior segments. $\mathrm{Am}$ J Ophthalmol. 2004;138:988-994.

14. Bahler CK, Hann CR, Fjield T, Haffner D, Heitzmann H, Fautsch MP. Second-generation trabecular meshwork bypass stent (iStent inject) increases outflow facility in cultured human anterior segments. Am J Ophthalmol. 2012;153:1206-1213.

15. Hunter K, Fjield T, Heitzmann H, Shandas R, Kahook MY. Characterization of micro-invasive trabecular bypass stents by ex vivo perfusion and computational flow modeling. Clin Ophthalmol. 2014;8:499-506.

16. [No authors listed]. The Advanced Glaucoma Intervention Study (AGIS): 7. The relationship between control of intraocular pressure and visual field deterioration. Am J Ophthalmol. 2000;130:429-440.

17. Quaranta L, Biagioli E, Riva I, Tosoni C, et al. Effect of trabeculectomy and canaloplasty on intra-ocular pressure modifications after postural changes in open-angle glaucoma. Acta Ophthalmol. 2014;92(6): e498-e499.
Clinical Ophthalmology

\section{Publish your work in this journal}

Clinical Ophthalmology is an international, peer-reviewed journal covering all subspecialties within ophthalmology. Key topics include: Optometry; Visual science; Pharmacology and drug therapy in eye diseases; Basic Sciences; Primary and Secondary eye care; Patient Safety and Quality of Care Improvements. This journal is indexed on Submit your manuscript here: http://www.dovepress.com/clinical-ophthalmology-journal

\section{Dovepress}

PubMed Central and CAS, and is the official journal of The Society of Clinical Ophthalmology (SCO). The manuscript management system is completely online and includes a very quick and fair peer-review system, which is all easy to use. Visit http://www.dovepress.com/ testimonials.php to read real quotes from published authors. 